\title{
BLENDED LEARNING \& MOOC: PERSPECTIVE OF A COURSE OF A HIGHER EDUCATION INSTITUTION
}

\author{
Filomena Soares ${ }^{1}$, Ana Paula Lopes ${ }^{2}$ \\ ${ }^{1}$ Polytechnic of Porto (P. PORTO) / ESHT - ESMAD (PORTUGAL) \\ ${ }^{2}$ Polytechnic of Porto (P. PORTO) / ISCAP - CEOS - CEPESE (PORTUGAL)
}

\begin{abstract}
The word MOOC (Massive Open Online Courses) has its origins in an experience carried out by George Siemens and Stephen Downes in 2008 based on the theory of connectivism and social constructivism. This worldwide phenomenon appeared as an evolution of the Open Educational Resources (OER) movement. They are a new style of online classes that allow any person with web access, anywhere, usually free of charge, to participate through video lectures, computer graded tests and discussion forums which have been taking the attention of many higher education institutions around the world. The purpose of this paper is to give us an overview of how MOOCs and Blended Learning can be used with as an educational strategy in a Mathematics Course of "non Mathematic" degree programs. The pedagogical strategy embraced in this venture, was to combine the potentialities of some, already available, "good" OER, with a blended working scheme established side by side with the course development, regarding fundamental issues considered as prerequisites to it. We will explain the specific contents involved, as well as the general and specific objectives and outcomes, the evaluation procedures established for the course support and development, finishing with a summary of the completion results. We did not want to discover the "wheel", it is from common knowledge for decades, but to present alternative ways to make a good use of it.
\end{abstract}

Keywords: Online Learning, Massive Open Online Courses, Higher Education, Blended Learning.

\section{INTRODUCTION}

Mathematics, in particular Math teaching is a topic widely analysed and scrutinized in various circles and educational degrees ([1],[2],[3] , among many others). As Math teachers, dedicated exclusively to Higher Education, we daily face the usual and widespread problems that are closely related to aptitude and acquired skills of students with which we work, mainly students from Bachelor and Advanced Technical Degrees in the Management area.

We teach at the Polytechnic of Oporto (P. Porto), the greatest Portuguese Polytechnic Institution with more than 20,000 people among students, teachers and researchers, and in this paper we will be referring to students from the School of Hospitality and Tourism (ESHT), with the central core areas in Management Studies applied to Tourism, Hotel and Restaurant. The students involved in this work are from the three undergraduate Management degrees in ESHT, namely, Catering and Restaurant Management (CRM), Hotel Management (HM) and Tourist Activities Management (TAM). These degrees comprise, at the first semester of the first year, a course of Quantitative Methods (QM) that aims to deepen and consolidate the previous knowledge in Mathematics, as a funding course for any degree in the Management area, following Math knowledge construction from Mathematics taught in secondary education, in Science and Technology Course and in Course on Socioeconomic Sciences.

It must notice that these degrees don't have Mathematics as a nuclear course, therefore for students who join these degrees Math is not a compulsory curricular unit throughout High School. This fact contributes to the generalized heterogeneity in terms of mathematical knowledge and skills in a classroom of the 1st year, where only a minority has a background of 12 years of Mathematics. This appears to bring about a generalized type of "antibody" or "trauma" that becomes an invisible start up barrier we must overcome every single year. This problem is, unfortunately, much more common (and old) than one could expect and far from being just a personal feeling ([4] to [10]), just, somehow, minimized when the Mathematics courses analyzed are from degrees where the Math A National Exam is compulsory as mandatory Specific Exam to enter Higher Education Institution (HEI) in Portugal, as it happens for all degrees in Engineering, for example (for further details see [11]).

An "optimal" solution is utopic and unreachable, but scudding and hiding behind this paradigm won't have any impact or improve anyone's academic path. We must remember that can only be reached if 
students and teachers' development and practice goes further beyond their scientific and academic training. In this sense, not possessing any "magic wand" we can only base, second and betake our own and several others experiences ([12] to [15]), even at a College-level [16], trying to make good use of the new technological advances and making an effort to perceive what can reach our students that already go beyond the "millennials", implementing different plans, developing new strategies, encouraging students' participation and engagement through digital and technological resources (trying to take advantage of students' digital skills), among several other stratagems and schemes.

\section{THE POPULATION AND SAMPLE CHARACTERIZATION}

The background differences between the Mathematic level students have, when entering these Management degrees, is a real problem we have to face in Quantitative Methods course, as we have already stated. However, despite all information available it is not easy to determine which of the required Exams students use for their entrance grade in $\mathrm{HEI}$ in Portugal and we have to conduct direct inquiries, depending on the goodwill of the students, so that we can carry out some sort of "cross" analysis, since we do not have direct access to Specific Exam use as the Entrance Test. Note that the public grade of $\mathrm{HEI}$ entrance is a pondered average of their secondary studies (three years) and the Specific Exam they choose from "list", that are, for the degrees in study: 04 Economy, 18 Portuguese and 17 Applied Mathematic to Social Sciences (MACS) or Geography (see Table 1 - to clarify the difference between Entrance Tests with the corresponding codes and exams to be performed [11]).

Table 1. Entrance Tests and Exams to be performed to enter Portuguese HEI

\begin{tabular}{|c|c|c|c|c|c|c|c|}
\hline \multicolumn{2}{|c|}{ Entrance Tests } & \multicolumn{2}{|c|}{ Exams to Perform } & \multicolumn{2}{|c|}{ Entrance Tests } & \multicolumn{2}{|c|}{ Exams to Perform } \\
\hline 01 & German & 501 & $\begin{array}{l}\text { German (initiation } \\
\text { - Biennial) }\end{array}$ & 02 & $\begin{array}{l}\text { Biology and } \\
\text { Geology }\end{array}$ & 702 & $\begin{array}{l}\text { Biology and } \\
\text { Geology }\end{array}$ \\
\hline 03 & Drawing & 706 & Drawing A & 04 & Economy & 712 & Economy A \\
\hline 05 & Spanish & 547 & $\begin{array}{l}\text { Spanish (initiation } \\
\text { - Biennial) }\end{array}$ & 06 & Philosophy & 714 & Philosophy \\
\hline 07 & $\begin{array}{l}\text { Physics and } \\
\text { Chemistry }\end{array}$ & 715 & $\begin{array}{l}\text { Physics and } \\
\text { Chemistry A }\end{array}$ & 08 & French & 517 & $\begin{array}{l}\text { French } \\
\text { (continued - } \\
\text { Biennial) }\end{array}$ \\
\hline 09 & Geography & 719 & Geography A & 10 & $\begin{array}{l}\text { Descriptive } \\
\text { Geometry }\end{array}$ & 708 & $\begin{array}{l}\text { Descriptive } \\
\text { Geometry A }\end{array}$ \\
\hline \multirow{2}{*}{11} & \multirow{2}{*}{ History } & 623 & History A & \multirow{2}{*}{12} & \multirow{2}{*}{$\begin{array}{l}\text { History of Culture } \\
\text { and Arts }\end{array}$} & \multirow{2}{*}{724} & \multirow{2}{*}{$\begin{array}{l}\text { History of } \\
\text { Culture and } \\
\text { Arts }\end{array}$} \\
\hline & & 723 & History B & & & & \\
\hline 13 & English & 550 & $\begin{array}{l}\text { English (continued } \\
\text { - Biennial) }\end{array}$ & 14 & Latin & 732 & Latin A \\
\hline \multirow{2}{*}{15} & \multirow{2}{*}{$\begin{array}{l}\text { Portuguese } \\
\text { Literature }\end{array}$} & \multirow{2}{*}{734} & \multirow{2}{*}{$\begin{array}{l}\text { Portuguese } \\
\text { Literature }\end{array}$} & \multirow{2}{*}{16} & \multirow{2}{*}{ Mathematics } & 635 & Mathematics $\mathrm{A}$ \\
\hline & & & & & & 735 & Mathematics B \\
\hline \multirow{3}{*}{17} & \multirow{3}{*}{$\begin{array}{l}\text { Mathematics } \\
\text { Applied to Social } \\
\text { Sciences }\end{array}$} & 635 & Mathematics A & \multirow{3}{*}{18} & \multirow{3}{*}{ Portuguese } & \multirow{3}{*}{$\begin{array}{l}639 \\
239\end{array}$} & \multirow{3}{*}{$\begin{array}{l}\text { Portuguese } \\
\text { Only for severe } \\
\text { deaf }\end{array}$} \\
\hline & & 735 & Mathematics B & & & & \\
\hline & & 835 & MACS & & & & \\
\hline 19 & Mathematics $\mathrm{A}$ & 635 & Mathematics A & & & & \\
\hline
\end{tabular}

The problem when accessing public data [17], is that the Specific Exam performed is not directly related to the Secondary School Field of Studyln the next section, we will describe our students background as they presented when asked in a small enquiry at the beginning of the scholar year, since according to the available data (see [18], for examplel) we can only summarize the training areas of the enrolled students not having access to their Math academic path. In Table 2 we present the data available for the enrolled students at the first phase of the National Application Process, in the 2016/17 school year, in the three undergraduate degrees of the ESHT [18]. 
Table 2. Secondary education courses attended by ESHT candidates First phase of the National Application Process - 2016/17

\begin{tabular}{l|cccc|c}
\hline & DEGREE & CRM & HM & TAM & \multirow{2}{*}{ TOTAL } \\
\cline { 1 - 3 } HIIGH SCHOOL AREA & & 6 & 5 & 3 & 14 \\
C60+C80 - Science and Technology & 3 & 7 & 3 & 13 \\
C62+C81 - Socioeconomic Sciences & 15 & 17 & 22 & 54 \\
C64+Other Art Courses & 3 & 1 & 2 & 6 \\
Technical/Professional Courses & 1 & 8 & 1 & 10 \\
Other Courses & 2 & 3 & 6 & 11 \\
\hline \multicolumn{1}{c|}{ TOTAL } & 30 & 41 & 37 & 108 \\
\hline
\end{tabular}

Looking at these numbers, one can easily anticipate a somewhat "black future", since only the students from Science and Technology and Socioeconomic Sciences had Mathematics during the three High school years (27 in 108). Data upgrade will be given in the next section since we have three phases of the National Application Process to the HEI, as well as several repeating students from the HM degree (regarding CRM and TAM degrees, we don't have this "figure" since it is the first year these are functioning in ESHT).

\subsection{Registered Students - Population}

Using the current official data on the number of enrolled students in the QM course, we present our population in Table 3. However, we cannot work on these since we do not have the data for all of them. Only a few of these students attend the presential sessions - 4 hours per week for HM and GRC and 3 hours per week for TAM (which has another curricular unit of Quantitative Methods II, in the second semester, with a weekly workload of 3 hours with a program distinct and unique focus on Descriptive Statistics and Probabilities).

Table 3. Registered students results

\begin{tabular}{|c|c|c|c|c|c|}
\hline \multirow{2}{*}{$\begin{array}{l}\text { Quantitative Methods } \\
\text { Results }\end{array}$} & \multirow{2}{*}{$C R M$} & \multicolumn{2}{|c|}{$H M$} & \multirow{2}{*}{ TAM } & \multirow{2}{*}{ TOTAL } \\
\hline & & $\begin{array}{c}1^{\text {st }} \\
\text { Reg. }\end{array}$ & Rep. & & \\
\hline Registrations & 29 & 50 & 53 & 43 & 175 \\
\hline Assessed & 24 & 38 & 10 & 30 & 102 \\
\hline Approved & 13 & 22 & 4 & 14 & 53 \\
\hline
\end{tabular}

From these registered students, we cannot access further connectable data. At this stage, as we have already mentioned, we depended on the willingness and concern of the students to pass on to us the information we requested for this analysis, but only some of them attended our call (see Table 4 - next section).

\subsection{Responding Students - Sample Characterization}

All the data presented in this section were obtained via an anonymous survey (Goggle form), specifically designed for students' field of studies, Math background characterization and support materials evaluation.

\subsubsection{Students Sample per Degree}

In table 4 is a direct comparison between the number of students registered in these $\mathrm{CU}$ and the number of responsive ones. In the following subsections, we will work with percentages in order to facilitate all the result interpretation and comparison between the different degrees. 
Table 4. Answers obtained - Comparison Registered students results

\begin{tabular}{l|cccc|c}
\hline \multirow{2}{*}{$\begin{array}{l}\text { Quantitative Methods } \\
\text { Results }\end{array}$} & CRM & $\begin{array}{c}1^{\text {st }} \\
\text { Reg. }\end{array}$ & Rep. & TAM & TOTAL \\
\hline Registrations & 29 & 50 & 53 & 43 & 175 \\
Answers & 21 & 22 & 12 & 32 & 87 \\
Answers/Registration (\%) & 72,4 & 44,0 & 22,6 & 74,4 & 49,7 \\
\hline
\end{tabular}

The link for accessing the questionnaires was sent to all the registered students but the number of answers from HM students was, comparatively, very small and this may be justified by two facts that should be mentioned: repeating students are less "assiduous", tending to attend less classes of this $\mathrm{CU}$, so they don't feel morally obliged to contribute and, on the other hand, regarding freshmen, only 3 (of the 50) attended our school class (with a schedule more compatible for the repeating students), the other classes where given to another teacher, although with our responsibility and supervision and, it seems they did not felt much compelled to register their opinion.

\subsubsection{Students' Field of Studies - High School Area}

In the next image (Fig. 1), we display the original secondary study fields of the sample students enrolled in all the three degrees. In Figure 2 we present separated images for each degree - CRM, TAM and HM to enable an eventual distinction between the different degrees, despite their common central and global development area - Tourism.

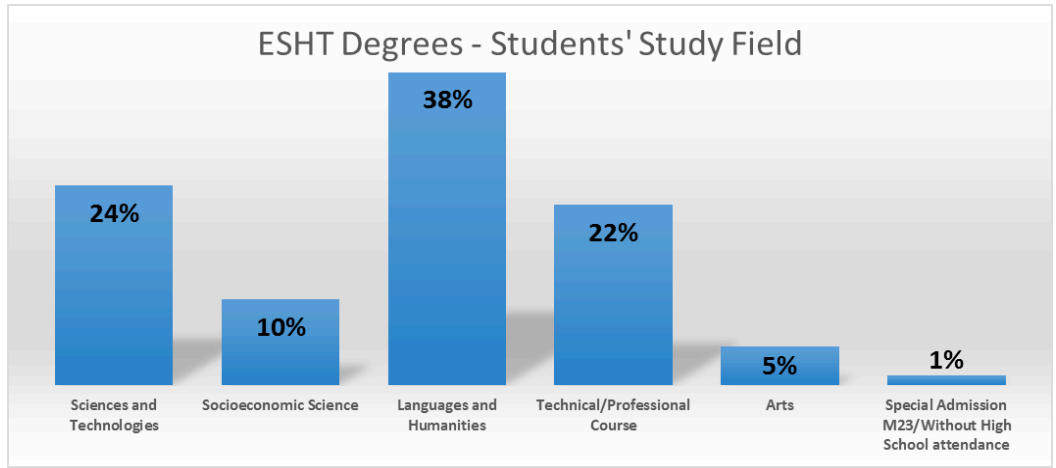

Figure 1. ESHT Degrees - Students' Study Fields

Since CRM and TAM degrees are very recent $(2016 / 2017$ is first year in ESHT) and HM is already functioning since 2010, this last has several repeating students enroled in QM course. These ones are students with a severe handicap in Mathematics, as it can be seen from the secondary areas of study - from the areas of Sciences and Technologies and Socioeconomic Sciences, we only registered $21 \%$ (in oposition to $47 \%$ of the students from the CRM degree and $41 \%$ from TAM degree). Globaly speaking we notice a percentage of only $34 \%$ of all students enroled in ST and ST areas.

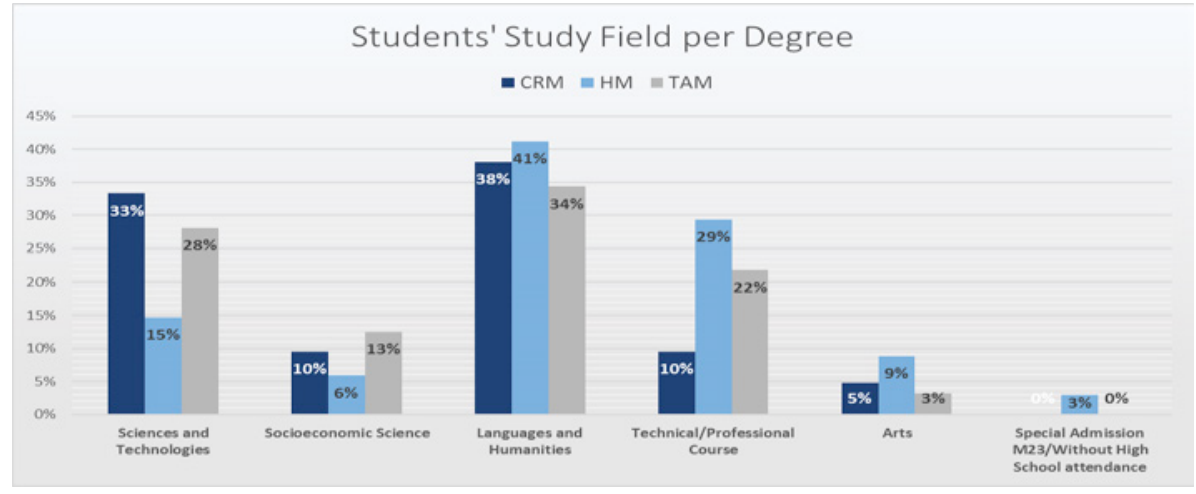

Figure 2. ESHT Students' Study Fields per degree 


\subsubsection{Students' Math background level}

In a similar way, we present in the next images (Fig. 3 and 4), the background level of Math in preuniversity studies. Note that these levels are presented in a descending order and that, supposedly, students should enter in the Management degrees with Math A or, at least, Math B frequency. As an image speaks more than words, we leave the following to an open analysis, only referring the direct (and obvious) relation between the study field and the Math frequency level.

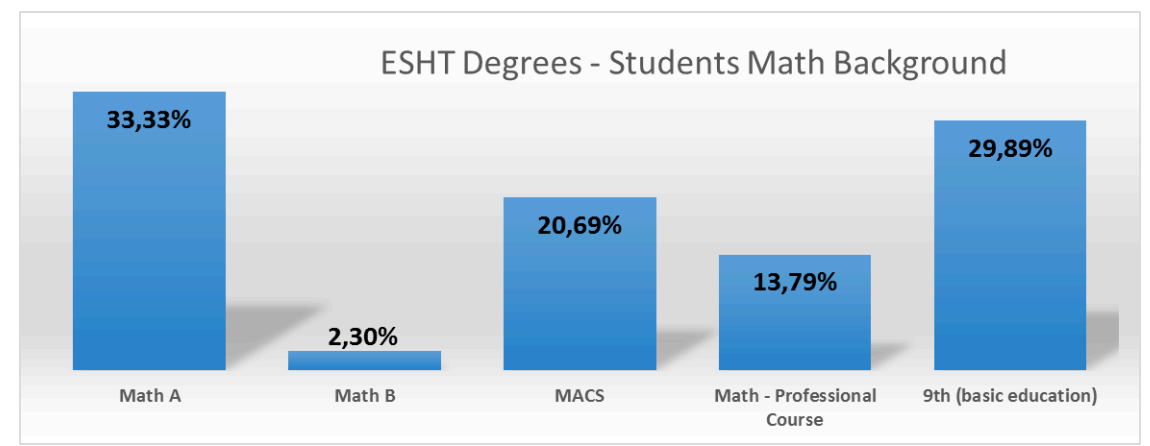

Figure 3. Quantitative Methods' students - First Year Students - Math Courses in pre-university

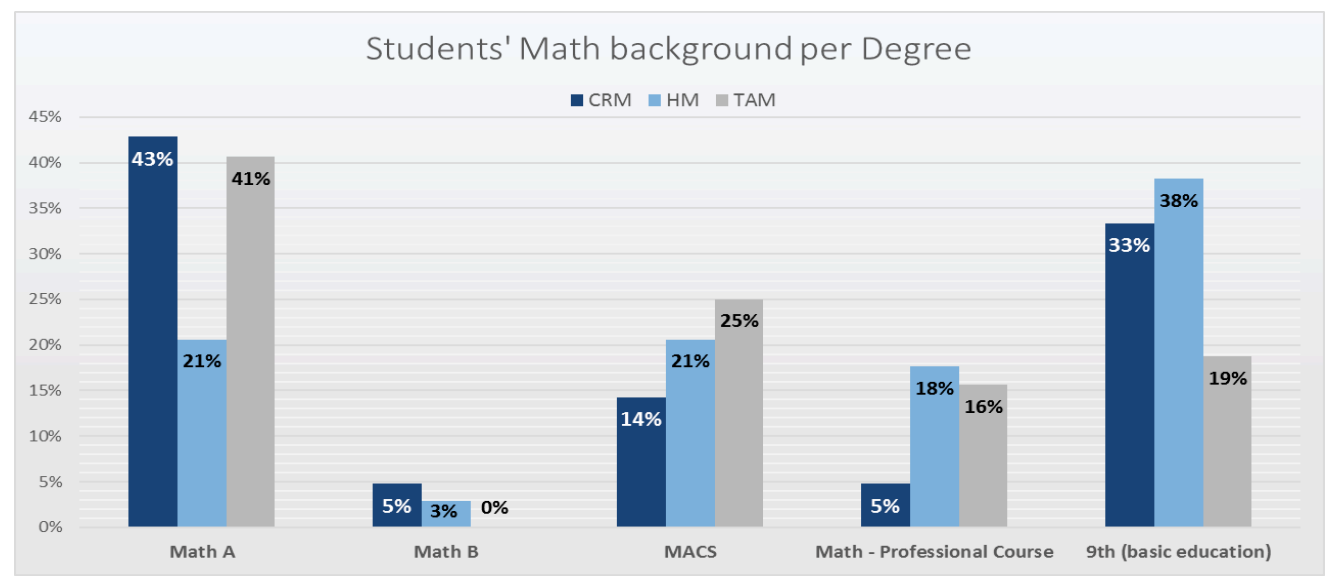

Figure 4. Pre-university Math Courses per degree

\section{METHODOLOGY}

Before we go any further, there are two key issues to have in mind: the program items to be addressed and developed, and the minimum conditions necessary for this work to be carried out with the majority of the students. So, at first, we must be acquainted with the background gaps they present, then try to overtake these and, simultaneously, being able to fulfill the course program.

In this sense, we will introduce, in the following section, a syllabus example from ESHT degrees and summarize the three pre-university curricula - Math A, Math B and MACS. We should also notice that the differentiated backgrounded "minds" is still larger than could be "expected" since almost $30 \%$ of the students did not have any curricular unit of Mathematics in their secondary studies for, at least, the three last years before entering to the superior education system (Fig. 3 last column).

Then, we describe the materials provided and used under b-learning model, essentially review items to be worked out by the students, online, asynchronously with the support of face-to-face sessions.

\subsection{Math Syllabus items}

\subsubsection{Quantitative Methods Syllabus}

It is commonly expected that, the first year of a degree in the Economics and Management field has in its curricula, at least, a course in General Mathematics, usually covering subjects like Differential 
Calculus, Integral Calculus, Statistics, among other possibilities. In Figure 5 we can see two extracts from Quantitative Methods' syllabus of TAM and HM degrees.
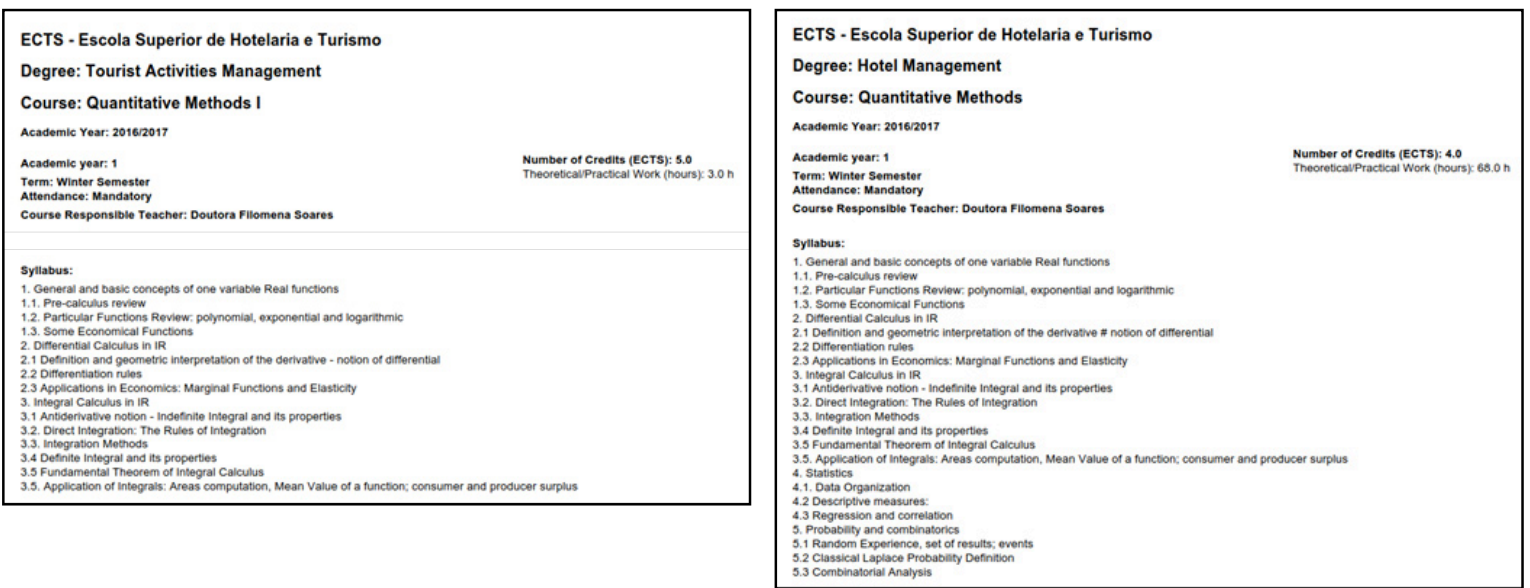

Figure 5. Math in Tourism Management Areas Degree - Syllabus examples

To attend the specific syllabus items involved in this process we will specifically work with the program global subjects - Differential and Integral Calculus (see Quantitative Methods I - Fig 5).

\subsubsection{Math Syllabus in Portuguese Secondary School}

Here, in order to abbreviate, our focus will just be the items that may be thought as prerequisites for Differential and Integral Calculus.

Following the "descending" order reasoning, in the Mathematics A contents, subjects are covered in more depth and there is a greater concern for scientific rigor. Thus, in a similar minimalistic way, the program comes down to the following main points along the three years: Functions and Graphics: generalities about functions; Introduction to Differential Calculus - Rational and Radical functions, Exponential and Logarithmic Functions; Rate of change and Derivative Function; Real Sequences ([19]). In what concerns the Mathematics B, the "middle" one in terms of work load, although present in the three school years, the weekly schedule (3h) is almost half of Mathematics A (5h), which implies that the subjects are often covered without the necessary "deepness". The issues in question are various, starting in the $10^{\text {th }}$ grade with Functions and Graphs - General - Polynomial Functions and Statistics, passing through Periodical Movements and Non-linear Movements, where the Rational Functions are addressed. The subjects end addressing Non-linear Continuous Models (exponential and logarithmic), finishing with Optimization Problems ([20],[21],[22]). Regarding MACS, just a twoyear course, the contents are, obviously, "shorter" than those of a three year one, like Math A or even $\mathrm{B}$, with the aggravating circumstance of less weekly working hours. Even the specific contents are quite different, never dealing with the notion of real function neither change rates or derivatives (it starts in the 10th year with Decision Support Methods - Mathematical Theory of Elections, Statistics and Financial Models, addressing the 11th year, Population Models and Graphs Models, passing through Probability Models and ending with Introduction to Statistical Inference [23]).

\subsection{Teaching methodologies}

The classes were organised in theoretical-practical sessions (expository and monitoring teaching). The contact hours in these courses were developed through actual sessions that articulate the expositive method (supported by documentation and practical examples presentation) and the exploratory and practical methods, trying to focus the proposed problems, whenever possible, in the nuclear degrees' areas.

We tried to guide the autonomous work organization through a constant use of the ESHT Moodle platform in a b-learning way and in a more intensive flipped model, with the "Math Without STRESS" (M100S) MOOC from P.Porto platform, essentially to what prerequisites is concerned. 


\subsubsection{Quantitative Methods Syllabus Items}

The contents' presentation was developed using videos, projections and board writing, explaining diverse examples and exhibiting application to real situations. Indication of relevant exercises to be solved by students during each class, in an autonomous way; suggestion of the main steps of solution, clearing doubts, monitoring and validating the student's individual work. The supporting materials, the syllabus and the pedagogical dynamics of the presential sessions that involve its theoretical and practical components, the teachers' support and monitoring, the activities of clearing doubts and solving the proposed problems and tasks, along with the activities for assessing knowledge were settled and based upon the course objectives and by the development of specific and general competencies defined for each theme. The assessment moments corresponded to the objectives defined for the course, focusing on the specific competencies. For each point of the syllabus, students had available the Supporting Texts and the Exercises Book (with the respective solutions), allowing them to manage their own learning process in an autonomous way. The Continuous Assessment allowed a constant interaction with students, promoting their autonomy and self-consciousness on reaching the established objectives, as well as the development of their responsibility for their own learning process.

\subsubsection{Pre-Calculus Items}

According to students' Mathematics backgrounds, we had to try to "fill" in the gap between high school and higher education. Consequently, there were several items that had to be worked prior to the advanced ones. This work relied on students' willingness to move forward and it was not an easy task for them, neither for the teachers involved. In the first month, there was a more intensive work load since, in trying to level up, the presential sessions were devoted to revision pre-calculus fundaments: Basic Calculus; Polynomials; Polynomial, Rational and Irrational Functions.

In this sense, students were encouraged to subscribe the MOOC "Introduction to Differential Calculus" (IDC) and use all available materials (see next section for description). This work was organized in order to accompany and support the review materials available in ESHT Moodle platform (more "dense" and just for revision purpose).

For further items, specifically, Exponential and Logarithmic Functions, Function Limit Notion, Function Continuity, Change Rates, Function Derivative and Derivative Applications, we developed from the scratch several supporting video-lectures in our own mother language, taking advantage of a handy tool that could contribute to complement the ones available in MOOC platform, trying to offer a friendly tool to support the management of each ones' learning commitment, which allowed several "flipped" moments, based on materials available on the ESHT Moodle platform as well as on MOOC one.

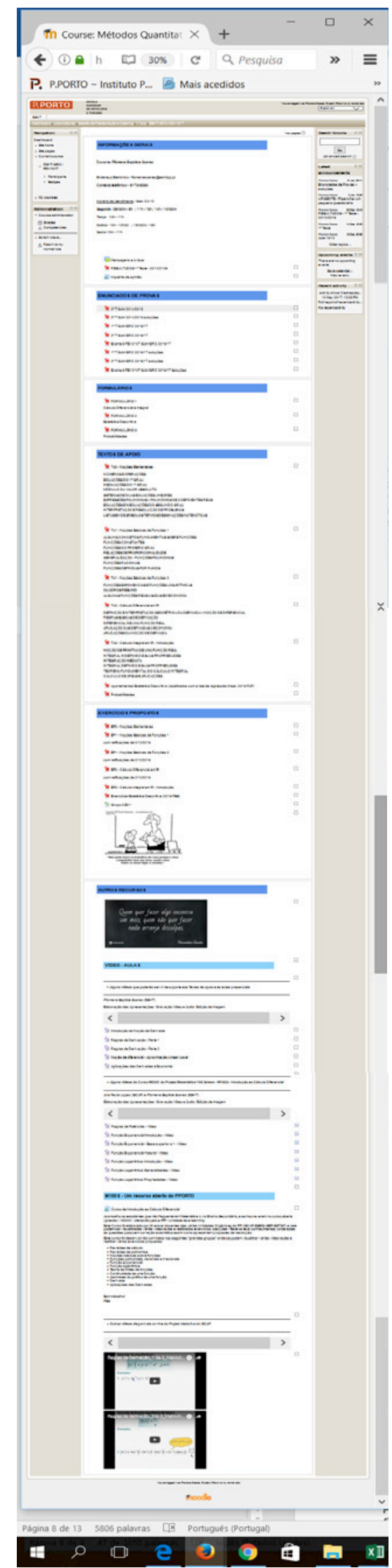

Figure 6. MQ Moodle page 


\subsection{Materials Development and Use}

There are two lines of work supported by online materials available in the distinct platforms: ESHT Moodle and M100S MOOC. In the first one, all resources, contents and their respective adjustment and modification were completely and directly manageable, as well as students monitoring. However, in MOOC platform, despite us being on the list off the platform developers and administrator profile teachers ([24],[25]) the adjustments are limited to one-off consensual issues and, since it is a global opened platform, contents are supposed to have a more "static" behaviour.

\subsubsection{ESHT Moodle Resources}

The QM page in Moodle (Fig.6) was divided in several sections, containing all types of support materials: General Information and Discussion Forum; Past Exams and Tests; Forms and Formulas; Supporting Texts; Proposed Application Exercises; Other resources - Videos, Quizzes and Links.

The use of each resource was calendarized and sequentially worked on presential sessions. The sections: Supporting Texts and Proposed Application Exercises were divided in several subsections comprising: Elementary Notions (numbers and operations, polynomials and polynomial expressions, equations and inequations, absolute value, polynomials, problem solving strategies); Functions Basic Notions 1 (Functions fundaments; Constant functions; First grade functions, Proportionality relations; Generalization - polynomial functions; Rational functions; Functions defined by branches); Functions Basic Notions 2 (Exponential and Logarithmic Functions; Economic Functions and applications); Differential Calculus in IR (Definition and geometric interpretation of the derivative - notion of differential, Basic rules of derivation, Differential of a real function, Application of derivatives to Economy, Other derivative applications).

Among "Other resources" there was a small description of the M100S MOOC and the corresponding link. Several other links were available to external resources, deliberately and specifically chosen for this course support, as well as some embed videos from MatActiva Project ([26]).

\subsubsection{M100S Description and Resources}

"Mathematics without STRESS" (or in its original version - in Portuguese - Matemática 100 STRESS - M100S) in a MOOC platform project launched by P. Porto, for incoming HE students to prepare them for post-high-school courses using mathematics. This MOOC consists of three different Courses: Probability and Combinatorics, Introduction to Differential Calculus (IDC) and Trigonometry and Complex Numbers, all with the same guidelines based on the following division: Information Spot; Math Diagnostic Test (MDT) - entry test, not mandatory; Modular subject division with two distinct subsections: Video-lectures and Sequential mini-quizzes; "Doubt Ed" - Open Discussion forum; Final "Assessment Test" finishing with Global Course evaluation.

The IDC course (see main page in Fig.7) subscribed by QM students comprises 18 randomized quizzes and 65 video-lectures, separated in the following topics:

- Basic Calculus review

- Understanding functions

- Exponential Function

- Function Limit Theory

- Asymptotes

- Derivative Applications
- Polynomials Review

- Polynomial, Rational and Irrational Functions

- Logarithmic Function

- Function Continuity

- Function Derivative

- Second Derivative and Applications 


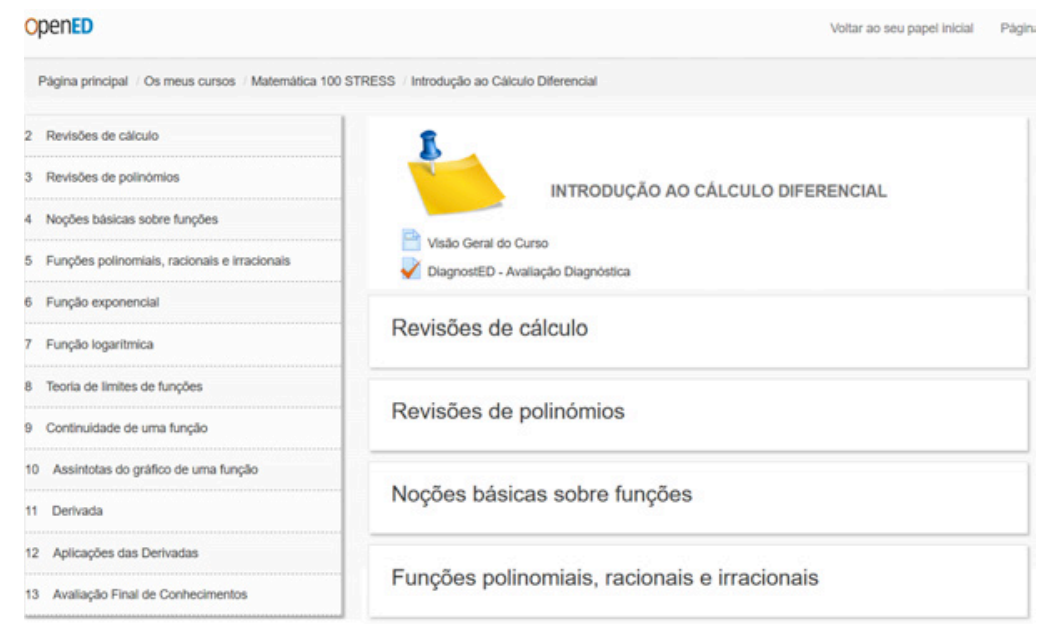

Figure 7. IDC Course main page screenshot

\subsubsection{Resource Use}

Based on Moodle Platform reports there were some interesting and quite unpredictable results since students seem more reluctant in using "new" resources than we were expecting, and we felt that, essentially freshmen, were very insecure and dependent on the traditional face-to-face lesson, relying essentially on Supporting Texts and Proposed Exercises. Despite the degree students are enrolled in, their behavior was not significantly distinct - when introducing a subject, students tend to "work" a little bit "more" - there were some "peaks" when starting with Power Rules (revision item), Logarithmic Functions and the Derivative notion, but the "movements" slow down afterwards.

\section{STUDENTS RESOURCE EVALUATION AND FINAL COMMENTS}

Four students, out of the 87 that took the survey (Table 4), stated that they never used the resources available (texts/exercises/videos) but they contributed to evaluating the relevance perception. Students were asked to "Rate the importance of having each of the following resources as a valid contribute to your learning process" in a 1 to 6 points (Likert Scale), where 1 meant "not-important" and 6 "very important" (see results Fig. 8). Notice that Exercises and Quizzes are on the "top" with $90,8 \%$ and $88,5 \%$, respectively, of positive feedback $(5+6)$ maintaining this position when it comes to strong positive relevance with $70,1 \%$ and $55,5 \%$ (only 6 ). Supporting texts are in the third "overall" relevance position with positive feedback from $69 \%$ while videos just achieve $64 \%$.

In the begging of this academic year our expectations were high regarding the promotion and use of new resources in the QM course, despite the heterogeneity of our students Math background. This small development was, in our and students' opinion, a hard but successful one, with a positive assessment feedback, to be continued and developed in the next years. Notice that considering the overall resources the mean evaluation grade was 4,97 and a median of 6 .

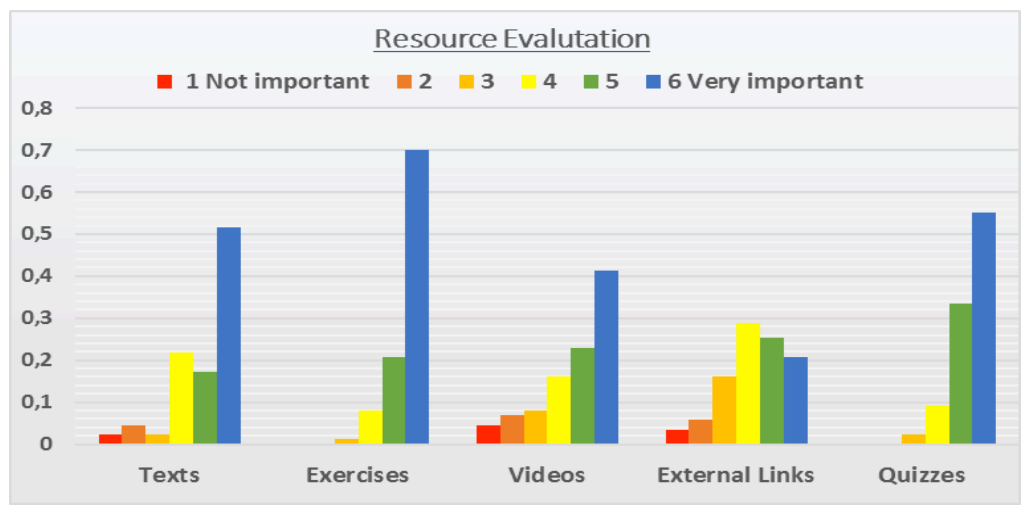

Figure 8. Resource Evaluation 
Despite these exciting and comforting results presented we have several difficulties to keep in mind when trying to act with our students in a personal and direct way, even supported by the use of new technologies: Number of students per class/teacher; High absenteeism rates; Student's low self confidence levels and motivation to learn, among several other time constrains and restrictions.

The academic success of these students was not confronted with their use of the available resources due to many time restrictions and Learning Analytics cross relations handicap with the online ESHT system, and we feel that much more should be done to reverse the weak results in QM. On the other hand, we sense that it is important that students feel that we care and that we will try to help them in their own learning process with all the means and resources available. Students who today join in HEI, already recognized as generation $Z$ or digital natives (who do not know the world without computers) are not easily stimulated with static teaching methods. It becomes thus urgent search for alternative strategies that streamline the teaching-learning process and involve students in building your academic path. This must be a constant concern in various levels of education, particularly in higher education, despite being an endless and exhausting challenge to teachers.

\section{REFERENCES}

[1] Kutaka, T. S. et al (2017). Connecting teacher professional development and student mathematics achievement: a 4-year study of an elementary mathematics specialist program. Journal of Teacher Education, (2), 140. doi:10.1177/0022487116687551

[2] Collis, K. (2016). Teachers and the new maths. Australian Mathematics Teacher, (3), 4.

[3] Ludwig, S. (2015). "Strategies in Teaching Math." Research Starters: Education (Online Edition)Research Starters, EBSCOhost (accessed May 10, 2017)

[4] Silva, E. S., Ghodsi, M., Hassani, H., \& Abbasirad, K. (2016). Research Notes: A quantitative exploration of the statistical and mathematical knowledge of university entrants into a UK Management School. International Journal of Management Education, 14440-453. doi:10.1016/j.jime.2016.10.002.

[5] C. Paralera Morales, A.M. Martín-Caraballo, A.F. Tenorio (2016) Math Skills in the First Year at The University of Undergraduate Students in Business Degree, EDULEARN16 Proceedings, pp. 8803-8811.

[6] Arnold, I. and Straten, J. (2012). Motivation and Math Skills as Determinants of First-Year Performance in Economics. The Journal of Economic Education, 43(1), pp.33-47.

[7] Harvey, S., Murphy, F., Lake, R., Jenkins, L., Cavanna, A., \& Tait, M. (2010). Diagnosing the problem: Using a tool to identify pre-registration nursing students' mathematical ability. Nurse Education In Practice, 10119-125. doi:10.1016/j.nepr.2009.04.007

[8] Lagerlöf, J. and Seltzer, A. (2009). The Effects of Remedial Mathematics on the Learning of Economics: Evidence from a Natural Experiment. The Journal of Economic Education, 40(2), pp.115-137.

[9] Ballard, C. and Johnson, M. (2004). Basic Math Skills and Performance in an Introductory Economics Class. The Journal of Economic Education, 35(1), pp.3-23.

[10] Ely, David P. and Hittle, Linda (1990). The Impact of Math Background on Performance in Managerial Economics and Basic Finance Courses. Journal of Financial Education, No. 19 (Fall 1990), pp. 59-61.

[11] DGES (2017). Provas de Ingresso 2017 - Ensino Superior Público. 4th ed. [ebook] Lisboa: Guias Digitais DGES. Available at: http://www.dges.gov.pt/guias/pdfs/GuiaPI2017_pub.pdf [Accessed 02 May 2017].

[12] M.P. Nunes, F. Soares, A.P. Lopes (2016) The background impact in HEI Math Lectures - An Experience in Math in the 1st year of Accounting and Management Degree, EDULEARN16 Proceedings, pp. 3955-3964.

[13] F. Soares, A.P. Lopes, M.P. Nunes (2016) Different Skills - Differentiated Learning Plans: A Strategic Compromise Towards Math Success, ICERI2016 Proceedings, pp. 3714-3724.

[14] A.P. Lopes, L. Babo, C. Torres (2015) The Impact of an Online Mathematics Education Project (Matactiva) on Higher Education Students, INTED2015 Proceedings, pp. 2921-2927. 
[15] Bettinger, E. and Long, B. (2009). Addressing the Needs of Underprepared Students in Higher Education. Journal of Human Resources, 44(3), pp.736-771.

[16] Logue, A., Watanabe-Rose, M. and Douglas, D. (2016). Should Students Assessed as Needing Remedial Mathematics Take College-Level Quantitative Courses Instead? A Randomized Controlled Trial. Educational Evaluation and Policy Analysis, 38(3), pp.578-598

[17] DGES - MCTES (2017a). Estatísticas do Concurso Nacional de Acesso de 2016. http://www.dges.mctes.pt/guias/pdfs/statcol/2016/.

[18] DGES - MCTES (2017b). Acesso ao Ensino Superior 2016 - Estatísticas. [online] Dges.mctes.pt. Available at: http://www.dges.mctes.pt/guias/pdfs/statcol/2016/StCEs16.pdf pp. S823 -S825 [Accessed 02 May 2017].

[19] Dgemecpt. (2013). Dgemecpt. Programa e Metas Curriculares Matemática A. Retrieved 02 January, 2017, from

http://www.dge.mec.pt/sites/default/files/ficheiros/programa_metas_curriculares_matematica_a _secundario.pdf

[20] Dgemecpt. (2002). Dgemecpt. Programa de Matemática B - 10. ${ }^{\circ}$ ano. Retrieved 04 January, 2017, from

http://www.dge.mec.pt/sites/default/files/Secundario/Documentos/Documentos_Disciplinas_nov o/Curso_de_Artes_Visuais/matematica_b_10_novo.pdf

[21] Dgemecpt. (2002). Dgemecpt. Programa de Matemática B - 11. ${ }^{\circ}$ ano. Retrieved 04 January, 2017, from http://www.dge.mec.pt/sites/default/files/Secundario/Documentos/Documentos_Disciplinas_nov o/Curso_de_Artes_Visuais/matematica_b_11_novo.pdf

[22] Dgemecpt. (2004). Dgemecpt. Ofício-Circular n. ${ }^{\circ} 19$ de 23/06/2004. Retrieved 04 January, 2017, from

http://www.dge.mec.pt/sites/default/files/Secundario/Documentos/Legislacao/oficio_circular_19_ 23-06-2004.pdfpp.-pp., City/State: Publisher, Year of Publication.

[23] Dgemecpt. (2001). Dgemecpt. Programa de Matemática Aplicada às Ciências Sociais. Retrieved 04 January, 2017, from http://www.dge.mec.pt/sites/default/files/Secundario/Documentos/Programas/mat_aplicada_cie n_soc.pdf

[24] A.P. Lopes, F. Soares, I. Vieira (2015) How to Feel "In Love" With Math - A Mooc Experience, INTED2015 Proceedings, pp. 326-332.

[25] A.P. Lopes, F. Soares (2016) The Development and Implementation of Math Projects in a HEI Expectations, Objectives, Experiences and Analysis, INTED2016 Proceedings, pp. 6522-6530.

[26] Babo, L., J. Azevedo, Lopes, A. (2008). The Active Mathematics Project at ISCAP. ENMA2008 International Conference on Engineering and Mathematics Proceedings Book ISBN: 978-84612-5331-9, 2008. 